\title{
Karyotype and chromosome banding in the Turkish desert woodlouse Desertellio elongatus (Crustacea, Isopoda, Oniscidea)
}

\author{
G. Röder ${ }^{\mathrm{a}}$, C. Steinlein ${ }^{\mathrm{b}}$, M. Schmid ${ }^{\mathrm{b}}$ and K. E. Linsenmair ${ }^{\mathrm{a}}$ \\ ${ }^{a}$ Lehrstuhl für Tierökologie und Tropenbiologie, Theodor-Boveri-Institut, Am Hubland, D-W-8700 Würzburg \\ (Federal Republic of Germany), and ${ }^{b}$ Institut für Humangenetik, Biozentrum, Am Hubland, D-W-8700 Würzburg \\ Received 23 October 1992; accepted 8 January 1993
}

Abstract. The karyotype of $D$. elongatus was investigated by means of C-banding, silver staining, and mithramycinand quinacrine fluorescent staining. The diploid chromosome number is $2 n=50$. C-banding shows pericentromerically localized constitutive heterochromatin in every chromosome. Two of the chromosome pairs carry two telomeric nucleolus organizer regions each. No heteromorphic sex chromosomes were found.

Key words. Karyotype; chromosome banding; Desertellio elongatus; Crustacea; Isopoda; Oniscidea.

Desertellio elongatus (Crustacea, Isopoda, Oniscidea) is a subsocial woodlouse native to semiarid regions, known to occur in the lava fields at the base of the northern slopes of Mount Ararat (East Anatolia, Turkey). The detrivorous woodlouse retreats into crevices and under stones while not foraging. The species belongs to the genus Hemilepistus in the widest sense ${ }^{1}$, which in turn is a member of the Porcellionidae family. While there have been extensive studies on various Oniscidea (called Oniscoidea in the older literature) concerned with the chromosome number and karyotype after conventional staining $^{2-6}$, significant banding studies in Isopoda have to our knowledge only been done on the aquatic isopod Asellus aquaticus, suborder Asellota ${ }^{7-12}$. The present paper examines the karyotype of $D$. elongatus and compares it with the results found for other Oniscidea. The results obtained by various banding techniques are described in detail.

\section{Materials and methods}

For the present study, females with a marsupium were used 3-8 days after parturial molt. They were kept at $25-30{ }^{\circ} \mathrm{C}$. Colchicine solution $0.3 \%$ was injected with a syringe into the marsupium of the female $24 \mathrm{~h}$ before preparation. The embryos (mancas) in various stages of development were then flushed out and maintained under hypotonic conditions (double-distilled water) for $15 \mathrm{~min}$. They were then transferred into a solution of 3 parts methanol and 1 part acetic acid for fixation. The cells were separated by up- and down-pipetting (in $50 \%$ acetic acid) of the individual slashed embryos, which had previously been lacerated with a scalpel, and applied to slides. During this process, the slides were placed on a hot plate at $43^{\circ} \mathrm{C}$.

C-banding, $\mathrm{AgNO}_{3}$-staining, mithramycin and quinacrine mustard fluorescent staining were carried out according to Schmid et al. ${ }^{13}$. The fluorescent staining was evaluated with a Zeiss fluorescence microscope; excita- tion was at $450-490 \mathrm{~nm}$ (filter combination BP $450-$ 490/FT510/LP520).

The animals examined were laboratory-bred descendants of a wild population imported in 1987 from Turkey by K. E. Linsenmair. A total of 103 embryos from 10 females were used, but metaphases were found in only 43 embryos.

\section{Results}

The metaphase count shows a diploid chromosome number of $2 n=50$ for $D$. elongatus (fig. 1a). In figures $1 \mathrm{~b}$ and $1 \mathrm{~d}$, the 50 chromosomes have been formally arranged into karyotypes presenting 25 chromosome pairs. The pairs $1-24$ are metacentric to submetacentric, the chromosome pair 25, however, is acrocentric or telocentric. The chromosomes 1-24 are of decreasing sizes (fig. 1b, d). Silver staining or mithramycin treatment (figs 1d, 2a, details see below) further distinguishes the chromosomes 1 and 4 from the others by means of their nucleolus organizer regions (NORs).

The constitutive heterochromatin, with its dark appearance following C-banding, is found exclusively in the centromeric region of each chromosome. The less condensed chromosomes in figure $1 \mathrm{c}$ show that this region consists of two pericentromeric C-bands arranged at each side of the centromere.

Staining with the GC-specific mithramycin reveals a very bright fluorescence of the pericentromeric heterochromatin. Furthermore, the NORs located on the short arm telomeres of chromosome pairs 1 and 4 exhibit a very faint mithramycin fluorescence (fig. 2a). As expected, the GC-rich pericentromeric heterochromatin is not stained with the AT-specific quinacrine mustard (fig. 2b). $\mathrm{AgNO}_{3}-$ staining, which stains the NORs which were active in the preceding interphase, displays the two NORs of chromosome 1 and 4 in a telomeric arrangement (fig. 1d) like that found with mithramycin. None of the staining techniques showed heteromorphic sex chromosomes. 


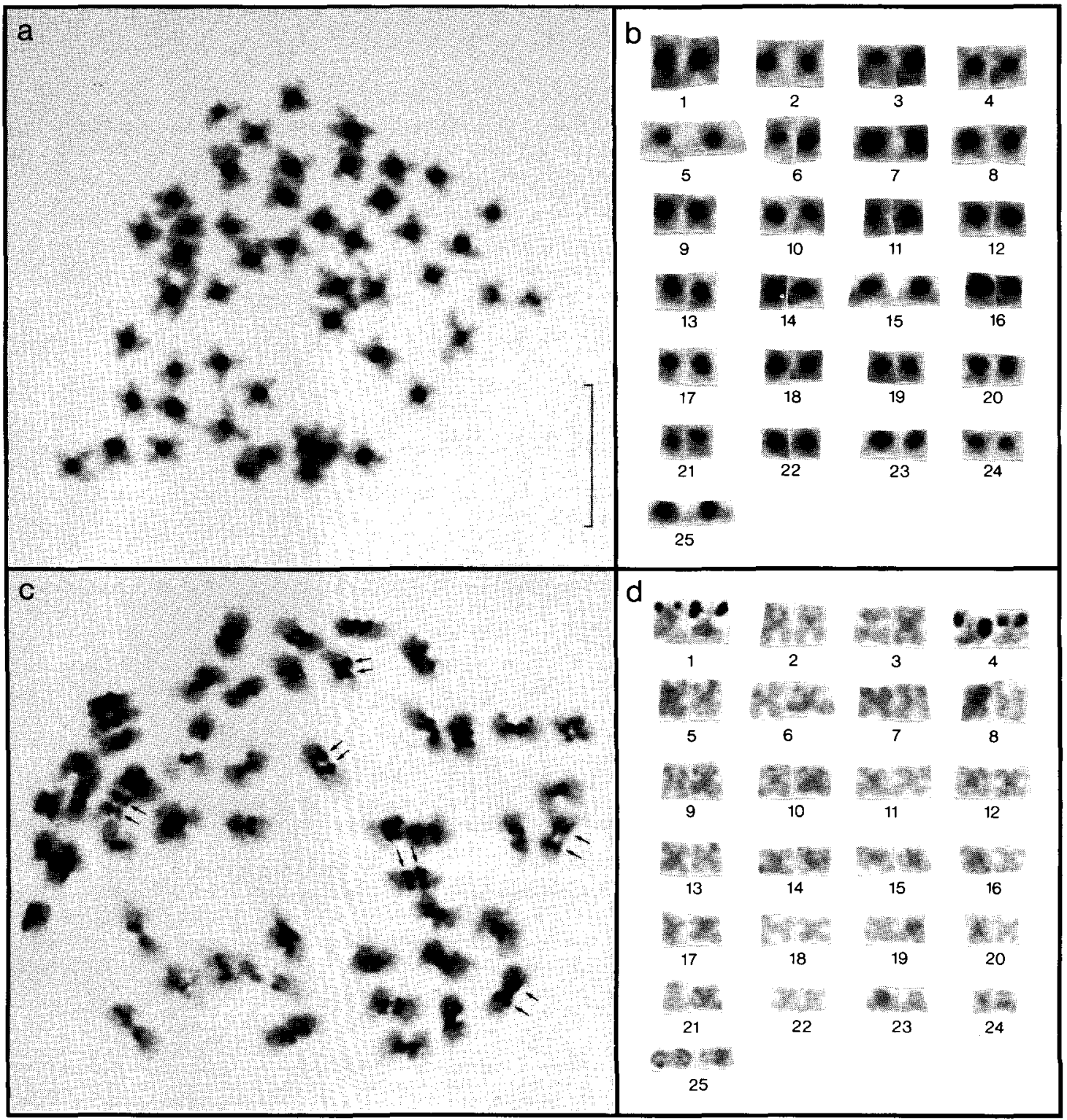

Figure 1. a Mitotic metaphase of Desertellio elongatus, showing C-banding (the bar represents $10 \mu \mathrm{m}$ ). b Chromosomes of the metaphase presented in (a), arranged as karyotype. $c$ Mitotic C-banded metaphase with elongated chromosomes in which the pericentromeric heterochromatin blocks (arrows) can be seen. $d$ Silver-stained karyotype of $D$. elongatus. The nucleolus organizer regions in chromosome pairs 1 and 4 are darkly stained.

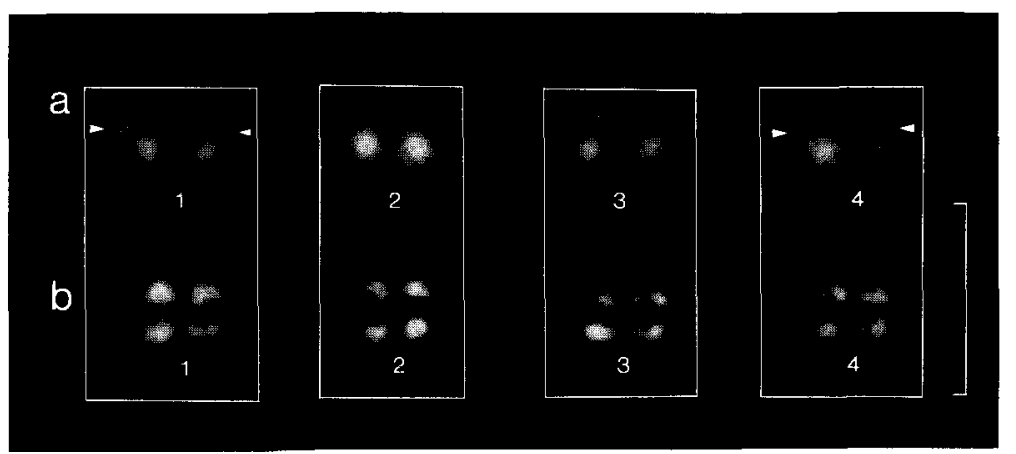

Figure 2. $a$ The four largest chromosome pairs of Desertellio elongatus after mithramycin fluorescent staining. The arrows indicate the fluorescing nucleolus organizer regions. $b$ The largest chromosome pairs showing quinacrine mustard fluorescence (bar represents $10 \mu \mathrm{m}$ ). 


\section{Discussion}

Whereas Vandel ${ }^{14}$ reports chromosome numbers of $\mathrm{n}=28$ for the 3 Porcellionidae species (Porcellio gallicus, P. scaber and P. laevis), as do Imai and Makino ${ }^{3}$ for $P$. scaber, Teichmann ${ }^{2}$ found $2 \mathrm{n}=50$ in 7 species of this family (including $P$. scaber and $P$. laevis). Mittal and Pahwa found $2 \mathrm{n}=50$ for $P$. laevis ${ }^{6}$ and $P$. rathkei ${ }^{5}$, but $2 \mathrm{n}=48$ in $P$. assamensis ${ }^{6}$. Hill's ${ }^{15}$ finding of $2 n=34-36$ for Nagara modesta (Porcellionidae) deviates considerably. Thirty studies on further Oniscidea species belonging to other families reported a chromosome number of $n=25$ or $2 n=50$ in 4 cases, whereas some of the other 26 studies showed highly variable numbers ( see summary in Teichmann ${ }^{2}$ ). The $D$. elongatus studied here fits this picture quite well: as a member of the Porcellionidae, it also shows the chromosome number of $2 n=50$, which apparently predominates in this family. The C-bands of $D$. elongatus have a pericentromeric position. The heterochromatin is typically located in this position in the chromosomes of most animal species. This is in contrast to the findings on Asellus aquaticus, where C-bands can be demonstrated in only few telomeres, usually in those carrying the NORs ${ }^{9}$.

Like A. aquaticus ${ }^{7}$, D. elongatus also possesses NORs on two chromosome pairs, as mithramycin and $\mathrm{AgNO}_{3}$ staining showed. Unlike $A$. aquaticus, in which not all NORs are labeled by $\mathrm{AgNO}_{3}$-staining in the mitotic metaphases ${ }^{10}$, all NORs can be stained with silver in $D$. elongatus, so that they were apparently active in the preceding interphase.

Neither the inspection of the general chromosome morphology nor the study of the heterochromatin portions showed the existence of sex chromosomes in D. elongatus. Within the Isopoda, however, sex chromosomes have only been demonstrated in Jaera marina (Asellota) ${ }^{16}$ and in Tecticeps japonicus (Flabellifera) ${ }^{17}$ using cytogenetic techniques, and the beginning of the differentiation of sex chromosomes has been postulated for a population of $A$. aquaticus (Asellota) ${ }^{11}$. Among the Oniscidea, no heteromorphic sex chromosomes were found in various older studies using conventional cytogenetic techniques (including $P$. laevis) ${ }^{2}$, whereas Mittal and Pahwa show female heterogamety in $P$. rathkei ${ }^{5}$ and in $P$. laevis ${ }^{6}$, and find no heteromorphic sex chromosomes in males of $P$. assamensis ${ }^{6}$. Since the present paper is restricted exclusively to aspects of chromosome morphology, the results of crossing experiments which do suggest the existence of sex chromosomes in the Oniscidea ${ }^{18,19}$ are not considered here. Many findings, particularly those for Armadillidium vulgare ${ }^{19.20}$, suggest that the sex in some Oniscidea is at least partially determined by cytoplasmatic factors, which in turn are influenced by environmental conditions (particularly temperature). The monogeny (progeny of individual females with sex ratios deviating significantly from a normal distribution) occurring in this context can be observed in our laboratory population of $D$. elongatus (Röder, unpublished). Since the present investigations were performed on embryos whose sex could not be determined morphologically, we can make no conclusive statement on the presence of morphologically differentiated heterosomes in $D$. elongatus.

1 Lincoln, R. J., Bull. Br. Mus. nat. Hist. (Zool.) 20 (1970) 109

2 Teichmann, H., Mitt. Hamburg. Zool. Mus. Inst. 60 (1962) 1.

3 Imai, G., and Makino, S., Jap. J. Genet. 16 (1940) 75.

4 Vandel, A., Bull. Biol. France Belg. 68 (1934) 419

5 Mittal, O. P., and Pahwa, S., Cytobios 29 (1980) 17.

6 Mittal, O. P., and Pahwa, S., Experientia 37 (1981) 343.

7 Di Castro, M., Prantera, G., Marchetti, E., and Rocchi, A., Heredity 39 (1977) 259.

8 Di Castro, M., Prantera, G., Marchetti, E., and Rocchi, A., Caryologia 32 (1979) 81

9 Rocchi, A., Prantera, G., and Di Castro, M., Caryologia 33 (1980) 401

10 Di Castro, M., Prantera, G., Cipriani, L., and Rocchi, A., Genetica 60 (1983) 163.

11 Rocchi, A., Prantera, G., Lanza, V., and Di Castro, M., Chromosoma 89 (1984) 193.

12 Pelliccia, F., Di Castro, M., Lanza, V., Volpi, E. V., and Rocchi, A., Chromosoma 100 (1991) 152.

13 Schmid, M., Haaf, T., Geile, B., and Sims, S., Chromosoma 88 (1983) 69.

14 Vandel, A., Bull. Biol. France Belg. 81 (1947) 154

15 Hill, R., Chromosoma 3 (1948) 232.

16 Staiger, H., and Boquet, Ch., Experientia 10 (1954) 64

17 Niiyama, H., Cytologia 21 (1956) 38.

18 Lueken, W., Z. VererbLehre 97 (1966) 345.

19 Juchault, P., and Legrand, J. J., Monitore zool. ital. (N.S.) Monogr. 4 (1989) 359

20 Bull, J., Evolution of Sex Determining Mechanisms. Benjamin Cummings Publ. Company, Menlo Park, California 1983. 